$/ p<0.01 /)$, though there were no significant differences in the mean actual level of hemoglobin A1c in the sera, or comparing the body mass index (BMI) between the two investigated groups.

Cholesterol levels were significantly higher in both Scleredema-DM patients group taking $/ p<0.01 /$ or not taking $/ p<0.05 /$ statins compared to similar control diabetic patient groups. Concerning the triglyceride, also a higher levels of triglyceride were found in Scleredema-DM patients who were taking statins $/ p<0.05 /$, compared Control-DM patients who were also taking statins, but no difference were shown in triglyceride levels between the Scleredema-DM group and the Control-DM group both who were not treated by statins.

Conclusions: Scleredema can be assessed by a simple skin-examination and might be a risk factor for stroke in patients with DM. Patients with scleredema are associated with increased cholesterol and triglyceride levels and a higher incidence of stroke compared to matched DM control population.

Disclosure of Interest: None declared

DOI: 10.1136/annrheumdis-2017-eular.2553

\section{AB0618 A UNIQUE ULTRASOUND PATTERN OF ADIPOSE TISSUE IN SYSTEMIC SCLEROSIS PATIENTS: A COMPARISON WITH RHEUMATOID ARTHRITIS PATIENTS AND HEALTHY CONTROLS. TWO SIDES OF ADIPOSE TISSUE INVOLVEMENT IN SYSTEMIC CHRONIC INFLAMMATORY DISEASES}

C. Rotondo ${ }^{1}$, R. Fanizzi ${ }^{1}$, A. Chialà ${ }^{2}$, M.G. Anelli ${ }^{1}$, G. Righetti ${ }^{1}$, M. Nivuori ${ }^{1}$, E. Praino ${ }^{1}$, L. Dinoia ${ }^{1}$, S. Lopriore ${ }^{1}$, G. Laselva ${ }^{1}$, C. Scioscia ${ }^{1}$, F. Cacciapaglia ${ }^{1}$, G. Lapadula ${ }^{1}$, F. lannone ${ }^{1} .{ }^{1}$ Deto - Rheumatology Unit, Bari University, Bari; ${ }^{2}$ Internal Medicine Unit, P.O. Valle d'Itria, Martina Franca (TA), Italy

Background: Systemic sclerosis (SSc) and rheumatoid arthritis (RA) are both chronic and systemic inflammatory diseases, involving connective tissue. The adipose tissue is acknowledged as an immune organ that secretes numerous inflammatory signals and it is supposed playing an important role in up-regulation of inflammatory status. A few data are published on altered white adipose tissue (WFT) distribution in patients (pts) with RA. None data are available about WFT distribution in SSc pts

Objectives: We aimed to characterize the subcutaneous adipose tissue (total (sWFT); superficial (SsWFT); inner (IsWFT)) and visceral adipose tissue (vWTF) thickness, evaluated by ultrasound (US) of abdominal adipose tissue, in SSc pts, with different body mass index classes (BMI), comparing with RA pts and healthy controls (HC)

Methods: 42 SSc pts, 57 RA pts and $12 \mathrm{HC}$ were recruited in this study. WFT measurements were assessed, using US (7.5 MHz probe), along the xiphoumbilican line: sWFT thickness (distance between the inner edge of the skin at the outer edge of the alba line (AL)), SsWFT (lobular upper zone of sWFT), IsWFT (sWFT- SsWFT); vWFT thickness (distance between the inner edge of the $\mathrm{AL}$ and the peritoneal line).

Results: No subject enrolled had metabolic syndrome. RA pts had thicker vWFT $(15.6 \pm 7.6 \mathrm{~mm})$ than SSc pts $(10.8 \pm 5.8 \mathrm{~mm})$ or HC $(10.1 \pm 3.8 \mathrm{~mm})(p=0.001)$. In particular, the upper-weigh RA pts had vWFT $88 \%$ thicker than upper-weight $\mathrm{HC}$ and the RA obese pts had vWFT $87 \%$ thicker than obese $\mathrm{HC}$. While, the upper-weight SSc pts had vWFT 22\% thicker than upper-weight $\mathrm{HC}$, and the SSc obese pts had vWFT 16\% thicker than obese HC. Positive correlations were found between all WFT measures and BMI in RA pts and $\mathrm{HC}(p \leq 0,05)$. In SSc $p t s$ we found lack of correlation between SsWFT and BMI $(r=0.232 ; p=0.145)$. Of note, only in SSc pts we observed different US WFT patterns (fig. 1a, fig. 1b) characterized by rearrangement of normal sWFT structure ( $\mathrm{HC}$ fig. 1c and RA pts fig. 1d). These structural rearrangements consisted in the absence of adipose lobules, replaced by hypoechoic - anechoic areas (fig.1a) (attributable to edema), or by hyperechoic lines and spots (fig.1b) (attributable to fibrotic replacement of
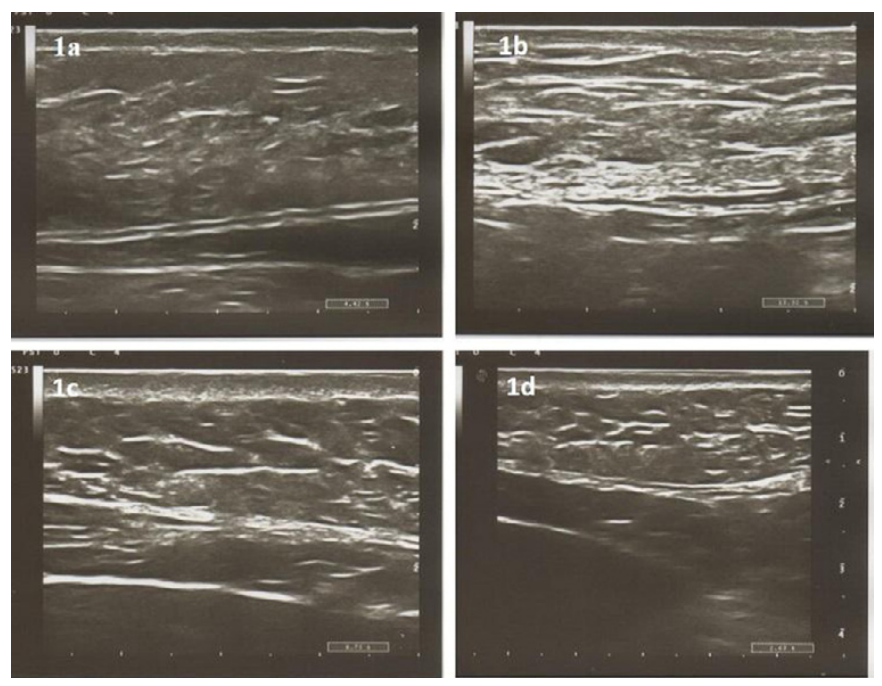

subcutaneous abdominal fat), independently by SSc diffuse or SSc limited skin subset.

Conclusions: In SSc and RA the WFT is abnormal. The WFT in RA seems be altered just for dimension and distribution, in particular the vWFT is overexpressed; it might be due to vWFT hyperactivity induced by inflammatory status. In SSc, the WFT is altered in the structure of sWFT. A direct involvement of sWFT in pathologic mechanism of SSc is supposed. An edema phase and a fibrotic phase of abdominal sWFT can be hypothesized, independently by skin involvement. If these findings will be confirmed by fat histological analysis, the US of WFT might be an important tool for the clinicians to identified the earlier stage and/or the active phase (edema) of SSc, in order to support physicians in the decision making about the treatment management.

Disclosure of Interest: None declared DOI: 10.1136/annrheumdis-2017-eular.5228

\section{AB0619 CONNECTIVE TISSUE DISEASE-ASSOCIATED INTERSTITIAL LUNG DISEASE TREATED WITH CYCLOPHOSPHAMIDE OR RITUXIMAB: A UNICENTRE, OPEN-LABEL AND COMPARATIVE STUDY}

C. LóPez-Medina ${ }^{1}$, F.J. Godoy-Navarrete ${ }^{2}$, P. Peinado-Villén ${ }^{2}$, P. Font-Ugalde ${ }^{1}$, M.C. Castro-Villegas ${ }^{1}$, R. Ortega-Castro ${ }^{1}$, J. Calvo-Gutiérrez ${ }^{1}$,

L. Ladehesa-Pineda ${ }^{1}$, L. Bautista-Aguilar ${ }^{1}$, A. Escudero-Contreras ${ }^{1}$

E. Collantes-Estévez ${ }^{1}$. ${ }^{1}$ Rheumatology, Hospital Universitario Reina Sofía de Córdobal Imibic/ Universidad de Córdoba; ${ }^{2}$ Universidad de Córdoba, Córdoba, Spain

Background: To date, rheumatologists do not have curative treatments for connective tissue disease-associated interstitial lung disease (CTD-ILD) (1), therefore an stabilization of the disease is considered as a therapeutic success. One of the most frequent drugs used for achieving this goal is Cyclophosphamide (CYC); however, in the last years there has been an increasing interest in the use of Rituximab (RTX) as a treatment for CTD-ILD.

Objectives: To compare long-term effectiveness of CYC vs. RTX as a treatment in patients with CTD-ILD.

Methods: Unicentre and retrospective study in which it was analyzed clinical and image data of 26 CTD-ILD patients treated with CYC or RTX between June 2004 and December 2016.

Previously, we checked that baseline characteristics and baseline levels of Pulmonary Function Tests (PFTs) in both groups were similar by using Fisher and T-student tests.

The primary outcome of the study was the stabilization of PFTs or HRTC (High Resolution Tomography Computed Tomography) considering as relapse: a) a deterioration $\geq 10 \%$ in FVC (Forced Vital Capacity), or b) a decrement $\geq 15 \%$ in DLCO (diffusing capacity of carbon monoxide), or c) a worsening in HRCT. The prognostic effect of each treatment on stabilization was evaluated using the Kaplan-Meier method and Long Rank test.

Subsequently, values of FEV1 (forced expiratory volume in one second), FVC, DLCO and DLCO/VA were compared 12 months after the beginning of the treatment with their corresponding baseline levels in both groups, using paired T-test. Finally, direct comparison between the CYC and the RTX groups was performed at the 12-months time point using T-test.

Results: The study includes 20 women and 6 men with an average age of $58.9 \pm 14.2$ years. 14 patients had a diagnosis of Systemic Sclerosis whereas 12 had other types of CTD.

From the 26 patients, 15 received CYC and 11 RTX, according to the physician's decision. Both groups presented similar baseline characteristics and levels in PFTs.

The Kaplan-Meier method showed that the treatment had an influence on the stabilization of CTD-ILD, although long Rank test was non-significative. The average of months without relapse in CYC and RTX group was $59.79 \pm 9.50$ and $79.27 \pm 7.81$ respectively.

Patients in the CYC group did not present any changes in FEV1, FVC, DLCO and DLCO/VA levels during the first year of treatment. In contrast, patients in RTX group showed an increase of all PFTs levels during the first year of monitoring, although these differences were non-significatives. A direct comparison between both treatment groups after 12 months showed lower levels of all PFTs in CYC vs RTX, been DLCO/VA ( $67.30 \pm 10.69$ and $86.25 \pm 4.59$, respectively) statistically significative.

Conclusions: This study suggests, in patients with ILD-CTD, that CYC treatment stabilizes the lung function, whereas RTX shows a tendency to improve it. Also, patients with RTX treatment shows a larger mean time of stabilization than CYC group. However, large scale randomized controlled trials are needed to confirm these results.

References:

[1] Fischer A, du Bois A. Interstitial lung disease in connective tissue disorders. Lancet 2012;380:689-98.

Disclosure of Interest: None declared

DOI: 10.1136/annrheumdis-2017-eular.2072 